que a ação setorial focalizada, realizada pelo PSF, não pareceu ser capaz de alterar a perversa dinâmica da "lei do cuidado inverso", ou seja, imprimir avanços na promoção da eqüidade do acesso à atenção à saúde.

Fiquemos, neste momento, com esses dois pontos. O vazio programático da questão assistencial no SUS vê-se traduzido, nos debates acadêmicos e na agenda pública, no tema (em suas várias vertentes) da racionalização do sistema de oferta de serviços de saúde, seu financiamento e seus custos. Complementarmente, a eqüidade e a universalidade, associadas à integração da rede de serviços por níveis de complexidade, buscam dar conta da outra ponta: a defesa dos princípios da reforma sanitária que se materializaram institucionalmente no SUS. Nessa dimensão, verificase um dos perigos presentes nas encruzilhadas nebulosas que se apresentam para o avanço da proposta sanitária formulada nos anos 70, 80 e 90: ao se assumir o PSF como uma estratégia de mudança do modelo assistencial brasileiro, esvazia-se, paradoxalmente, a dimensão da política e tende a tomar seu lugar a dimensão técnica na busca de avaliação, monitoramento e aperfeiçoamento desse modelo.

Já no que diz respeito ao segundo ponto, a baixa capacidade que a estratégia assumida revelou para reverter a "lei do cuidado inverso", ela se configura como conseqüência natural do primeiro, exatamente pelo esvaziamento da dimensão da sua política, e também da sua dimensão social, nos esforços para se preencher esse "vazio programático da questão assistencial do SUS". $\mathrm{E}$ ao se perderem essas duas dimensões, vários temas são relegados pela agenda do debate público. Dentre eles, agora de forma crítica, pode ser salientada a ausência de um debate vigoroso sobre as implicações de se assumir, como política prioritária de saúde, uma estratégia formulada exatamente para um perfil de atenção à saúde que é o exato oposto do ideário que inspirou e fundamentou o SUS. Num movimento paradoxo, é como se, na ausência da dimensão da política na concepção e implementação da atenção básica no país, a simples "vontade política" e "criatividade brasileira" fossem suficientes para, num passe de mágica, arregimentar os "homens e mulheres de boa vontade" para enfrentar todas as forças presentes que constrangem exatamente a viabilidade da proposta de um SUS realmente democrático e que cristalize a saúde como um direito.

Mas o texto é instigante, ainda, por propor, de forma equilibrada e realista, a discussão da questão da atenção básica tendo, como estratégia, a saúde da família, embora francamente favorável, nas entrelinhas, à tese de que essa é uma estraté-

gia inquestionável, embora não necessariamente a única, para se atingir os objetivos do ideário sanitarista. No entanto, ela deixa de tratar uma dimensão, a meu ver das mais importantes, sobretudo quando a sua preocupação é produzir um ensaio teórico-conceitual: a difícil articulação entre os "determinantes da esfera macro e microssocial numa rede de fatores", com um perfil de complexidade não passível de ser resolvido, ou enfrentado, no âmbito do trabalho. Se a própria questão da articulação entre aquelas duas esferas demanda um esforço hercúleo para deslindá-la, o que não pode ser ignorado no caso da atenção básica é que, diante da ausência de propostas e projetos mais consistentes para a área da saúde e diante da complexidade daqueles grandes temas, o que se verifica é a proliferação de estudos e análises com traço acentuadamente empírico e de caráter micro, no geral, com a tônica na dimensão operacional do sistema de saúde e da própria atenção básica e, no outro extremo, de propostas que lançam mão de reflexões altamente abstratas e de cunho filosófico, quando não fortemente inspiradas no exoterismo, concorrendo, com isso, para o esvaziamento da discussão substantiva sobre os rumos e os novos significados que as políticas e programas de saúde vêm assumindo na atualidade. Mas é exatamente por esse "vazio programático", por mim entendido como a ausência de formulação de uma proposta substantiva para o setor, que atualize e avance nas propostas do ideário sanitário formulado no último quartel do século passado, que a oportunidade do texto se reafirma.

Juan Gérvas

Departamento de Salud Internacional, Escuela Nacional

de Sanidad, Madrid, España.

jgervasc@meditex.es

\section{Atención Primaria, de la teoría a la práctica}

La salud es un bien preciado, no un derecho. Lamentablemente, algunas constituciones ofrecen la salud como derecho, lo que crea graves confusiones. La salud depende de muchos determinantes y nadie puede "asegurarla" como derecho (y evitar la muerte). Las obligaciones de los poderes públicos respecto a la salud son: defensa de la salud (protección), incremento de la salud (promoción), evitación de enfermedades y de sus consecuencias (prevención) y organización de servicios clínicos (atención). Cuanto más cumplan estas cuatro obligaciones de política sanitaria, y más salud "produzcan" los poderes públicos, menos sanos se sentirán sus ciudadanos 
(“la paradoja de la salud", a más salud objetiva menos salud subjetiva).

La salud de una población depende poco de los servicios clínicos. Lo básico, si se desea incrementar la salud, es invertir en educación (especialmente, en educación de las mujeres). Otras políticas clave en la salud de la población son las de higiene de agua y alimentos, de vivienda, de trabajo, de justicia y de redistribución de riqueza. Todas estas políticas crean fuertes conflictos en su aplicación. Por ello, la democracia es fundamental para la salud, ya que es el sistema menos malo de solventar conflictos. Otra cosa es la "democratización de los servicios" que nunca se ha demostrado tenga efectos sobre la salud.

Algunos problemas de salud requieren atención clínica, y para ello existe un sistema sanitario. El objetivo del sistema sanitario es dar respuesta a la morbilidad y mortalidad innecesariamente prematura y sanitariamente evitable (en la literatura inglesa avoidable morbidity and mortality), y al sufrimiento consiguiente.

El sistema sanitario tiene dos componentes claros: (1) el que no ofrece servicios personales clínicos (salud pública, en todas sus variantes); y (2) el que ofrece servicios personales clínicos (con dos niveles, uno de atención primaria y otro de atención hospitalaria). Tristemente, muchas veces se confunden con los programas comunitarios ambos componentes, y se pierde eficiencia en sus capacidades. Hay que cooperar, pero sin confundir ni métodos ni personal.

El objetivo del sistema sanitario no es evitar la pobreza, ni combatir la injusticia social. Estos fines se logran eficientemente con otras políticas, no directamente sanitarias, de educación, de trabajo, de redistribución de riqueza, de justicia y de bienestar social. El sistema sanitario, en todo caso, puede paliar los efectos de la pobreza y de la injusticia social, pero "paliar" no es "evitar" ni "combatir". Paliar significa dar respuesta a la morbilidad y mortalidad innecesariamente prematuras y sanitariamente evitables ligadas a la pobreza y la injusticia social, así como diagnosticar y tratar apropiadamente la deshidratación infantil, o la tuberculosis (enfermedades típicas de la pobreza).

\section{Financiación y provisión de servicios sanitarios}

El sistema sanitario de un país en un momento dado es la expresión de una historia, de una economía y de una sociedad. En los países desarrollados, la Segunda Guerra Mundial fue el detonante que llevó al acuerdo social de considerar que el acceso a los servicios sanitarios no debía depender de las posibilidades económicas. Es decir, que correspondía al Estado la financiación de los servicios sanitarios, de forma que fueran accesibles a todos los enfermos con independencia del nivel económico del paciente.

Respecto a la organización de los servicios clínicos (la atención sanitaria), en todos los países desarrollados del mundo, con la notable excepción de Estados Unidos, los servicios clínicos públicos cubren a toda la población (y son accesibles para todos, según necesidad, no según capacidad de pago). La "cobertura" se refiere a la financiación. Los sistemas sanitarios son públicos cuando la mayor parte del gasto sanitario del país que se considere procede de fuentes públicas (bien impuestos generales, bien impuestos ligados al trabajo y a la producción de bienes).

En contraste con la financiación pública de los servicios sanitarios, en todos los países desarrollados del mundo la provisión de los servicios sanitarios de atención primaria es privada. Así, en Alemania, Australia, Austria, Bélgica, Canadá, Chequia, Dinamarca, Estonia, Eslovenia, Francia, Holanda, Irlanda, Italia, Japón, Letonia, Lituania, Noruega, Nueva Zelanda, Reino Unido, Suiza y Taiwán. Se basa en médicos generales (o de familia) que son profesionales independientes (de facto, pequeños empresarios), que cobran por acto o por capitación. La excepción se da en España, Finlandia, Islandia, Portugal y Suecia, con médicos generales funcionarios públicos, asalariados y que trabajan en equipos en centros de salud públicos.

El pago por capitación exige una "lista de pacientes", un "cupo", del que el médico general es responsable. Los médicos generales tienen función de filtro (gatekeeping) para el nivel especializado en los países en que cobran por capitación (Eslovenia, Holanda, Irlanda, Italia, Noruega y Reino Unido), y en España (el salario se complementa con un pago por capitación). El filtro y el pago por capitación se asocian a mejor control del gasto sanitario y a mejor salud de la población, sin que sepamos bien el porqué. La tendencia mundial es al establecimiento de la función de filtro del médico general. Por ejemplo, en Bélgica, Francia y Alemania, los especialistas han empezado a cobrar desde 2004 más por acto, si el paciente viene derivado tras visitar al médico general (lo que crea un filtro funcional, por presión del especialista sobre el paciente, para que lo derive el médico general).

La función de filtro pretende adecuar la intensidad de atención a la gravedad y/o rareza del proceso de enfermedad. Así, a través del filtro, los recursos tecnológicos se reservan para quienes probablemente los necesitan, y se evita el uso innecesario de los mismos por quienes no los necesitan (se evita el despilfarro económico, y el daño a la salud que provoca su uso indebido: 
prevención cuaternaria). El objetivo es prestar servicios de "máxima calidad, mínima cantidad, con tecnología apropiada, tan cerca del domicilio del paciente como sea posible".

\section{¿Atención primaria para pobres?}

La atención primaria es directamente accesible y debería cubrir a toda la población, no sólo a los pobres. Es atención primaria, de "primera", no de "primitiva" ni de "básica”. Se precisan médicos generales muy resolutivos, polivalentes, con mucha autonomía, autoridad y responsabilidad, con formación y recursos suficientes para ofrecer a la población una función de filtro. Se logran estos médicos con reformas pro-contenido (mejor formación y más recursos en atención primaria) y con reformas pro-coordinación (potenciación del papel de filtro). Estos médicos logran crédito y reputación de todas las capas de la población (y son las clases media y alta las que establecen la reputación social). Para ofrecer atención primaria de calidad no hay mucho que medir, hay mucho que hacer (resolver eficazmente problemas clínicos).

La atención primaria se puede ofrecer con médicos trabajando en solitario, o con equipos de médicos y otros profesionales, sin que se hayan demostrado las ventajas del trabajo en equipo (el equipo es una opción ideológica promocionada por la Organización Mundial de la Salud).

La atención primaria es atención clínica de calidad, prestigiada, que ofrece sólo la prevención de efectividad probada (y priorizada), y que colabora con la salud pública (pero no la sustituye).

\section{A autora responde \\ The author reply}

\section{Eleonor Minho \\ Conill}

Foi um privilégio ler as contribuições feitas pelos debatedores e agradeço aos Editores pela pertinência na escolha dos participantes, que permitiu intervenções com uma interessante diversidade complementar. Tentarei sintetizar alguns aspectos principais dessas intervenções de modo a estabelecer um diálogo entre todos. Assim, Campos destaca a existência de um desacordo cultural, epistemológico e político sobre a Atenção Primária, a qual enfrenta o peso de uma tradição sanitária adversa. Essa tradição, em contextos e de formas distintas, privilegiou o coletivo em detrimento da dimensão clínica dos serviços. Além disso, teria havido uma implementação excessivamente centralizada da estratégia da saúde da família, sendo o autor reticente quanto às possibilidades reais (mas não acerca da necessidade) de uma abertura na direção de uma política de reorganização dos serviços que possa combinar singularidades locais com as diretrizes do Sistema Único de Saúde (SUS). Acho sensato cotejar essa intervenção com àquela de Sampaio que, na qualidade de gestor, considera que esse engessamento operacional foi o ônus a pagar pelo avanço inquestionável de uma estratégia nacional num país de dimensões continentais como o nosso. No entanto, argumenta que isso garantiu a visibilidade para questões relacionadas com a organização dos serviços, rompendo o excessivo silêncio por parte da academia sobre essa temática. Sugere que estaria em curso um processo incremental de mudança da Atenção Primária à Saúde no Brasil, o que abre a possibilidade para que, partindo-se da acumulação institucional e da produção de conhecimentos existente, possamos circunscrever e insistir na construção de uma agenda de impasses a serem superados. Assinalei alguns que me parecem centrais e sobre os quais penso ter havido razoável concordância. Senão, é como diz Campos, a realidade insiste em contradizer conquistas, uma vez que a porta de entrada, em grandes centros, acaba sendo um cuidado pontual de pronto atendimento. $\mathrm{Ou}$ então, corre-se o risco de aprofundar a segmentação que se mantém apesar da implementação do SUS, constituindo-se a posse de um plano de saúde (de qualidade, muitas vezes, questionável) 